\title{
Nature and extent of human-elephant Elephas maximus conflict in central Nepal
}

\author{
Ganesh Pant, Maheshinar Dhakal, Narendra Man Babu Pradhan \\ Fiona LEVERINGTON and MARC HOCKINGS
}

\begin{abstract}
Human-elephant conflict is one of the main threats to the long-term survival of the Asian elephant Elephas maximus. We studied the nature and extent of human-elephant interactions in the buffer zones of Chitwan National Park and Parsa Wildlife Reserve in Nepal, through household questionnaire surveys, key informant interviews, site observations, and analysis of the reported cases of damage during January 2008-December 2012. During this 5 -year period 290 incidents of damage by elephants were reported, with a high concentration of incidents in a few locations. Property damage (53\%) was the most common type of damage reported. Crop damage was reported less often but household surveys revealed it to be the most frequent form of conflict. There were also human casualties, including 21 deaths and four serious injuries. More than $90 \%$ of the human casualties occurred during 2010-2012. More than two thirds of the respondents (70\%) perceived that human-elephant conflict had increased substantially during the previous 5 years. Despite the increase in incidents of human-elephant conflict in the area, $37 \%$ of respondents had positive attitudes towards elephant conservation. Our findings suggest that public awareness and compensation for losses could reduce conflict and contribute to ensuring coexistence of people and elephants in this human-dominated landscape.
\end{abstract}

Keywords Buffer zone, Chitwan National Park, conservation, human-elephant conflict, Nepal, Parsa Wildlife Reserve

\section{Introduction}

The Asian elephant Elephas maximus is categorized as 1 Endangered on the IUCN Red List (Choudhury et al., 2008), mainly as a result of loss and fragmentation of its habitat, and conflict with people (Sukumar, 1993). The

Ganesh PANT* (Corresponding author) and Maheshwar Dhakal Department of National Parks and Wildlife Conservation, PO Box 860, Kathmandu, Nepal E-mail ganeshpant@yahoo.com

Narendra Man Babu Pradhan Bird Conservation Nepal, Kathmandu, Nepal

Fiona Leverington and Marc Hockings School of Geography, Planning and Environmental Management, The University of Queensland, Brisbane, Australia

${ }^{*}$ Previously at: School of Geography, Planning and Environmental Management, The University of Queensland, Brisbane, Australia

Received 8 September 2014. Revision requested 14 November 2014. Accepted 4 March 2015. First published online 6 July 2015. population of wild Asian elephants is estimated to be 38,500-52,500, and captive elephants number c. 16,000 (Sukumar, 2006). As human populations have increased, the elephant population in most range countries has been declining as a result of loss and degradation of forest habitat, fragmentation of breeding populations and an increase in human-elephant conflict (Hoare, 1999; Perera, 2009), which are therefore priority areas of action for ensuring long-term survival of wild elephants both in Asia and Africa (Hoare, 2000; Sukumar, 2006). We follow Wilson et al. (2015) in referring to human-elephant conflict, but note that the objective is to enhance human-elephant coexistence (Redpath et al., 2015).

Human-elephant interactions that have a negative effect on people, elephants and the environment pose a challenge for biodiversity conservation (Parker et al., 2007). In Nepal $23 \%$ of land area falls within the protected area system (DNPWC, 2014), and there is increasing likelihood of conflict as populations of wildlife, humans and livestock are increasing. More than $40 \%$ of conflicts and $70 \%$ of human casualties from interactions with wildlife in Nepal involve human-elephant conflict (Bajimaya, 2012). People fear elephants because they damage crops, destroy property, and cause injury and death (Parker et al., 2007).

One of the predominant causes of human-wildlife conflict is the fear of being killed (Thirgood et al., 2005). Damage caused by wildlife can affect people's perceptions, especially when it exceeds a certain level of tolerance (Hill, 1998). Attitudes of local people are important in wildlife conservation and may vary according to gender, age, education and past experiences (Hill, 1998; Røskaft et al., 2007). Older people and those who have experienced damage caused by wildlife generally have more negative attitudes, whereas people with higher levels of education tend to be more positive towards wildlife (Røskaft et al., 2007). People living in rural areas were found to be more negative towards wildlife conservation than those living in urban areas, as they bear disproportionately the costs of damage caused by wildlife (Bandara \& Tisdell, 2003).

Wild elephants in Nepal occur in four isolated populations ranging over $10,982 \mathrm{~km}^{2}$ of forest habitat in the lowland Terai (DNPWC, 2008) and are estimated to number 107-145 (DNPWC, 2008; Pradhan et al., 2011). The eastern population comprises 7-15 individuals. In central Nepal the population increased from an estimated 13 individuals in 1980 to 21 in 1989 (Smith \& Mishra, 1992) and there are 
now estimated to be $20-25$ elephants, mostly residing in Parsa Wildlife Reserve and Chitwan National Park, and ranging over $>3,227 \mathrm{~km}^{2}$ of relatively intact forest habitat. The western and far western populations comprise $60-80$ and 15-20 individuals in Bardia National Park and Shuklaphanta Wildlife Reserve, respectively (DNPWC, 2008; Pradhan et al., 2011).

The habitat occupied by wild elephants in central Nepal has an estimated carrying capacity of at least 200 elephants. However, planning is needed to address human-elephant conflict if public support for elephant conservation is to be maintained (Smith \& Mishra, 1992). The elephant population in central Nepal has come into conflict with people relatively less than the eastern population (DNPWC, 2008). There was an increase in conflict around Chitwan National Park and Parsa Wildlife Reserve when elephants killed 11 people during a 10-month period in 2010-2011 but the reasons behind this sudden increase in incidents of conflict are not understood (Pradhan et al., 2011).

Human-elephant conflict is a serious concern for both protected area managers and local communities (Sitati et al., 2003), and the long-term future of elephants depends on the effectiveness of the measures taken to mitigate such conflicts (Sukumar, 2006; Hedges \& Gunaryadi, 2010). Such effectiveness requires a thorough understanding of the spatial and temporal patterns of conflict (Barnes, 2009); however, most mitigation measures are implemented on an ad hoc basis without the benefit of these data (Parker et al., 2007).

Bhatta (2006) emphasized the need for detailed assessment of human-elephant conflict in Nepal, including the nature and extent of damage caused by elephants, as a basis for developing mitigation measures. Despite the severity of the conflict there is no comprehensive strategy to guide mitigation measures, and most measures are reactive and implemented in response to a crisis situation following a major incident (Pradhan et al., 2011). In this context we attempt to understand the pattern of human-elephant conflict across the landscape of central Nepal.

\section{Study area}

The study was carried out in the buffer zones of Chitwan National Park and Parsa Wildlife Reserve, two adjoining protected areas in southern central Nepal (Fig. 1). The buffer zone of the Reserve extends over Bara, Parsa and Makawanpur districts and covers $298 \mathrm{~km}^{2}$. The human population in this buffer zone comprises 91,155 people, in 14,750 households (DNPWC, 2012b). The buffer zone of the Park extends over Chitwan, Nawalparasi, Parsa and Makawanpur districts and covers $750 \mathrm{~km}^{2}$. There are 223,260 people living there, in 36,193 households (DNPWC, 2012a). The buffer zone is a legally delineated area surrounding national parks or reserves to provide forest resources to local people. It is essentially an impact zone intended to reduce the pressure of local people on the Park and vice versa (DNPWC, 2012b).

\section{Methods}

Questionnaire surveys, key informant interviews and field observations were used to collect primary data during December 2012-January 2013. Secondary data were collected from the office records of the Park, Reserve and relevant Buffer Zone User Committees as well as from the literature.

Questionnaire survey Based on records from the Park and Reserve, and consultation with Park staff, we identified 48 settlements within the buffer zones of the Park and Reserve that were affected by damage from wild elephants within the previous 5 years. We used a questionnaire to survey 303 households in these settlements. Every 1oth household in each settlement was selected, and face-to-face interviews were conducted with the head of the household by field assistants who had been trained in survey methods. If the head of the household was not present, another senior member of the family was chosen for interview. If no one was present at home when the field assistants visited, the next household was selected for interview. Respondents gave their verbal consent prior to the interview, and none of the selected respondents declined to participate in the survey. Of 303 respondents 190 (63\%) were male and 113 (37\%) were female; 215 ( $71 \%)$ were from the buffer zone of the Park and $88(29 \%)$ were from the buffer zone of the Reserve. The mean age of respondents was $44 \pm \mathrm{SD}_{15}$ years, and the youngest and oldest respondents were 18 and 90 years of age, respectively.

Key informant interviews Semi-structured interviews were conducted with 30 key informants, including protected area managers, experts and representatives from conservation partners, and representatives from buffer zone organizations and the media. We recorded their knowledge of humanelephant conflict and its causes, and the mitigation measures implemented and their effectiveness. Twentyseven interviewees were male and three were female; 11 were community representatives, nine were park managers, seven were experts in wildlife research and management, and three were from the media.

Damage data and location mapping When local people experience human-elephant conflict they may report it to the relevant Protected Area Office through the Buffer Zone User Committee and claim compensation. It is estimated that c. $80 \%$ of incidents are reported (Basnet, 2011). We compiled data on damage caused by wild 


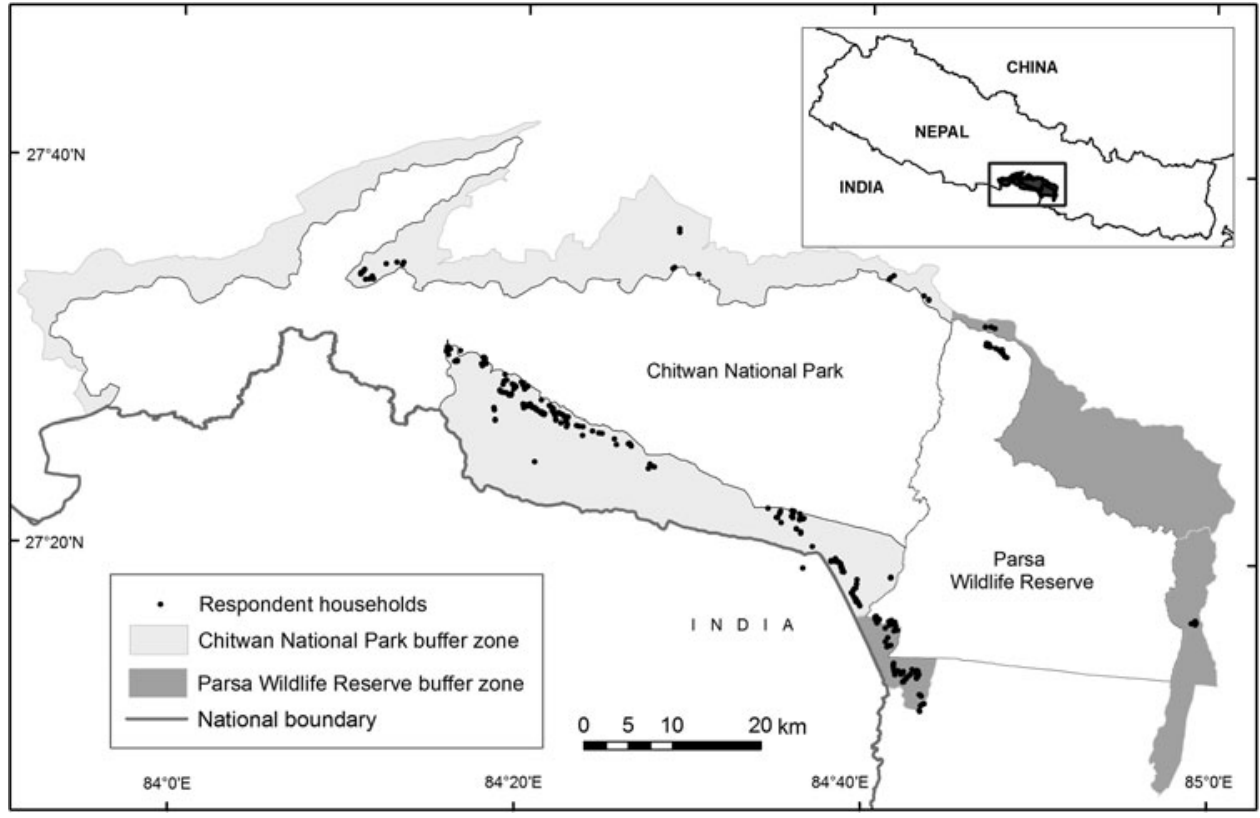

FIG. 1 Locations of respondent households in the buffer zones of Chitwan National Park and Parsa Wildlife Reserve, Nepal. elephants in the buffer zones during January 2008December 2012 from the offices of the Park and Reserve and the relevant Buffer Zone User Committees. To understand the spatial distribution of crop damage, human casualties and property damage caused by wild elephants, we visited the damage sites and recorded their geographical locations using a global positioning system.

Data analysis Both quantitative and qualitative techniques were used for data analysis. We used simple descriptive statistics in Excel (Microsoft, Redmond, USA), and SPSS v. 21.o (IBM, Armonk, USA). $\chi^{2}$ tests were conducted to determine the relationships between people's attitudes towards elephant conservation and the damage they had experienced. The geographical locations of incidents of human-elephant conflict were entered in ArcGIS v. 10.1 (ESRI, Redlands, USA) for spatial analysis. The value of estimated loss and compensation in USD was calculated from NPR using the median value of monthly mean exchange rates for USD to NPR during January 2008December 2012.

\section{Results}

Nature and extent of human-elephant conflict

During January 2008-December 2012268 households from the buffer zones of the Park and Reserve reported 290 incidents of human-elephant conflict. Of these, 250 households reported only one incident, 15 reported two incidents, two reported three incidents, and one household was affected four times. Households reporting damage represent $<_{1} \%$ of the
$>50,000$ households in the buffer zones of the Park and Reserve (DNPWC, 2012a, b). Most of the households surveyed (79\%) reported being affected by human-elephant conflict.

The damage caused by elephants was broadly categorized as property damage, crop damage or human casualty. Based on the reported incidents, property damage was the most common type, accounting for $53 \%$ of compensation claims (Table 1). In contrast, the survey data indicated that crop damage was the most frequently experienced form of human-elephant conflict ( $77 \%)$, followed by property damage $(24 \%)$ and human casualties $(3 \%)$. Paddy was the most raided crop in central Nepal, with $87 \%$ of the compensation claims related to paddy raiding, followed by wheat $(5 \%)$, maize (5\%) and banana (4\%). The survey data indicate that wild elephants also damage millet, sugarcane and mustard.

The claims for damage caused by wild elephants (excluding human death) during 2008-2012 were equivalent to USD 37,300 , comprising USD 22,060 for property loss, USD 13,340 for crop loss, and USD 1,900 for treatment for injuries (Table 1). The Park records show that compensation equivalent to USD 40,667 was paid to the families of people killed by wild elephants during this period. The mean annual household income in the rural central Terai region is USD 2,535 , and the mean household size is 5.6 people (CBS, 2011).

\section{Trends in human-elephant conflict}

The number of reported incidents of human-elephant conflict generally increased over the study period (Fig. 2). The number of incidents of crop damage reported decreased in 2012 compared to 2010 and 2011, and the number of incidents of property damage remained almost unchanged. There may have been under-reporting in the 2012 data, as 
TABLE 1 Types of damage caused by elephants Elephas maximus in the buffer zones of Chitwan National Park and Parsa Wildlife Reserve (Fig. 1) during 2008-2012, with the number of incidents reported, percentage of total incidents, total value of compensation, and mean value of compensation payments. Data were sourced from Chitwan National Park, Parsa Wildlife Reserve, and Buffer Zone User Committee records

\begin{tabular}{|c|c|c|c|c|}
\hline Type of damage & $\begin{array}{l}\text { No. of incidents } \\
\text { reported }\end{array}$ & $\begin{array}{l}\% \text { of total } \\
\text { incidents }\end{array}$ & $\begin{array}{l}\text { Total value of } \\
\text { compensation (USD) }{ }^{1}\end{array}$ & $\begin{array}{l}\text { Mean compensation } \\
\text { payment, USD }{ }^{1} \text { (range) }\end{array}$ \\
\hline Property damage & & 53 & 22,060 & $144(4-1,067)$ \\
\hline Stored grain only & 56 & & & \\
\hline House only & 48 & & & \\
\hline House and stored grain & 33 & & & \\
\hline Other & 16 & & & \\
\hline Crop damage & & 38 & 13,340 & $119(13-800)$ \\
\hline Paddy & 98 & & & \\
\hline Wheat & 5 & & & \\
\hline Maize & 5 & & & \\
\hline Banana & 4 & & & \\
\hline Human casualty & & 9 & $1,900^{2}$ & $475(111-1,076)$ \\
\hline Death & 21 & & & \\
\hline Injury & 4 & & & \\
\hline
\end{tabular}

${ }^{1} \mathrm{USD}_{1}=$ NPR 75

${ }^{2}$ Excludes compensation for death

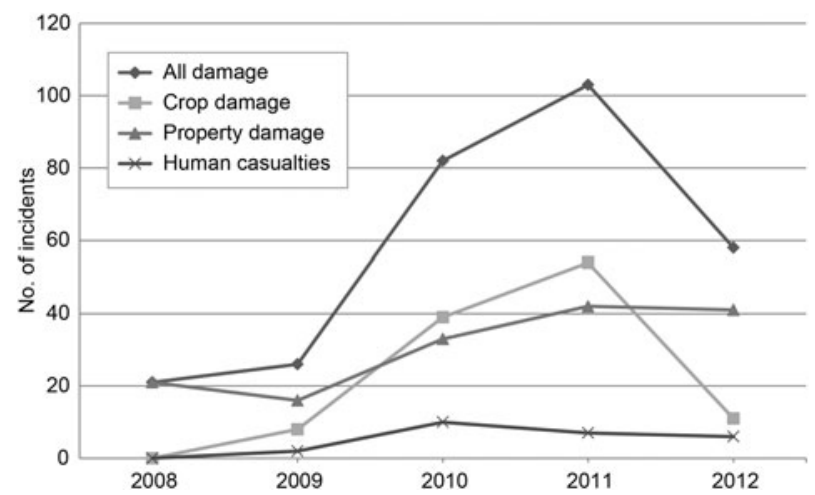

FIG. 2 Trends in incidents of human-elephant conflict in the buffer zones of Chitwan National Park and Parsa Wildlife Reserve (Fig. 1) during 2008-2012 for all types of damage, property damage, crop damage, and human casualties.

incidents that occurred in 2012 but were reported to the Protected Area Office and Buffer Zone User Committee after January 2013 were not included. More than $70 \%$ of the respondents to the household survey $(\mathrm{n}=303)$ believed that incidents of all types of damage by elephants had increased during the previous 5 years. Likewise, $80 \%$ of the key informants $(n=30)$ agreed that human-elephant conflict in central Nepal increased over this period.

\section{Temporal pattern of human-elephant conflict}

Based on compensation claims, incidents of humanelephant conflict have followed a seasonal pattern for all types of damage (Fig. 3a). Incidents of property damage were distributed throughout the year, with the highest number of incidents occurring in December. In contrast, crop damage peaked during July and SeptemberNovember, whereas numbers of incidents were not particularly high during December-June. The distribution of human casualties followed a similar pattern to property damage, with the highest incidence in December. The seasonality of damage by elephants as perceived by respondents broadly followed a similar pattern (Fig. 3 b).

More than $90 \%$ of the respondents in the household survey indicated that all types of damage occur mostly at night. However, there were mixed results for the timing of human casualties. Of the 25 casualties that occurred during the study period $60 \%$ occurred at night. All of the casualties that occurred during the day occurred in the forest, either in the protected area or in the buffer zone, except for one incident in Meghauli village development committee (the smallest administrative unit in rural areas), where a bull elephant entered the village while following a captive female elephant.

\section{Spatial pattern of human-elephant conflict}

Incidents of human-elephant conflict were not distributed uniformly throughout the study area (Fig. 4). Most incidents (93\%) occurred in the buffer zone of the Park, and only $7 \%$ were in the buffer zone of the Reserve. The buffer zones of the Park and Reserve encompass five districts of the central Terai, but incidents of human-elephant conflict were reported only from four districts: Chitwan, Parsa, Makawanpur and Bara. More than $80 \%$ of incidents were reported from Chitwan district, followed by $14 \%$ from Parsa, $2 \%$ from Makawanpur and $<1 \%$ from Bara. 

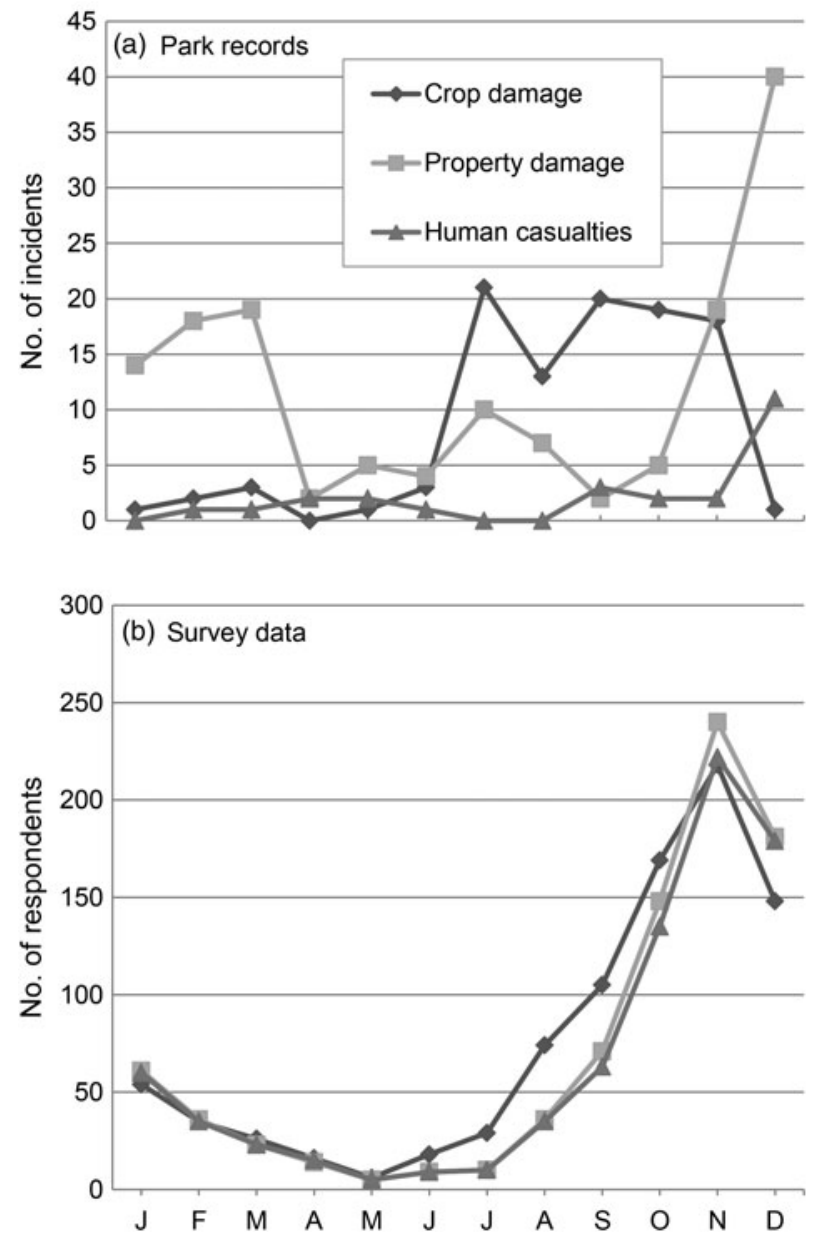

FIG. 3 Temporal patterns of human-elephant conflict in the buffer zones of Chitwan National Park and Parsa Wildlife Reserve (Fig. 1) during 2008-2012, based on records from the Park, Reserve, and Buffer Zone User Committees, and data from a questionnaire survey of households in the buffer zones.

Of 42 village development committees and two municipalities in the buffer zones of the Park and Reserve, 16 village development committees and one municipality were affected by damage caused by elephants. The intensity of damage varied among affected areas (Fig. 4). More than 100 incidents were reported from Ayodhyapuri village development committee; six village development committees reported 10-50 incidents each, and 10 reported $<10$ incidents. Eighty-eight percent of incidents occurred within 2 $\mathrm{km}$ of the protected area boundary (Fig. 5), and no incidents were reported $>5 \mathrm{~km}$ from the boundary in the buffer zones of either the Park or the Reserve.

\section{Attitudes of local people}

The survey respondents identified 14 species or categories of wild animals that are in direct conflict with people in this area: tiger Panthera tigris, rhinoceros Rhinoceros unicornis, elephant, sloth bear Melursus ursinus, wild pig Sus scrofa, spotted deer Axis axis, blue bull Boselaphus tragocamelus, mugger crocodile Crocodylus palustris, hare Lepus sp., jackal Canis aureus, leopard Panthera pardus, monkey, porcupine Hystrix indica and birds. Of 303 respondents $92 \%$ rated elephants as one of the most problematic wild animals. The next most commonly rated problematic animals, based on the severity of damage, were rhinoceros, wild pig, spotted deer, blue bull and tiger.

Some respondents $(37 \%)$ had positive attitudes towards conserving wild elephants, despite the increase in human-elephant conflict in the area. However, the survey did not reveal a statistically significant relationship between the level of damage experienced and people's attitudes towards elephant conservation $\left(\chi^{2}=1.549, \mathrm{df}=2, \mathrm{P}>0.05\right)$. Of 98 respondents with a positive attitude towards elephant conservation, $43 \%$ valued elephants as national property, $26 \%$ valued them as rare wildlife species, $24 \%$ believed that elephants are important in promoting tourism and $7 \%$ regarded elephants as a symbolic representation of God. Conversely, $83 \%$ of respondents who did not favour elephant conservation in this landscape considered elephants to be a threat to their lives, and $17 \%$ considered elephants to be a problem because of damage to crops and property. Female respondents were more likely to have negative attitudes than males $\left(\chi^{2}=7.024, \mathrm{df}=1, \mathrm{P}<0.05\right)$. There was no significant difference in attitude between people living in the buffer zones of the two protected areas $\left(\chi^{2}=1.149, \mathrm{df}=1, \mathrm{P}>0.05\right)$.

\section{Discussion}

The secondary data indicated that property damage was the most common form of damage by wild elephants for which compensation was claimed in central Nepal. However, the household survey indicated crop damage was experienced more frequently. This follows the same pattern as studies conducted in other countries (Sri Lanka, Campos-Arceiz et al., 2009; India, Sukumar, 1990; China, Zhang \& Wang, 2003; Africa, Hoare, 2000, Parker et al., 2007). The significant difference between compensation claims and survey data may reflect the fact that crop damage is less likely to be reported than property damage. This may be because the actual loss from crop damage is not significant compared to property damage, and local people tolerate a certain level of crop damage. It may also be attributed to people's reluctance to claim compensation for crop damage as there is no comprehensive package for compensation except in the case of human casualties.

Crop raiding is part of an elephant's optimal foraging strategy and there are two peak seasons of crop raiding: June-July, when maize and wheat mature, and September-November, when paddy becomes more palatable and nutritious (Sukumar, 1990; Pradhan et al., 2011). Paddy is the main field crop of the Terai region, and two 


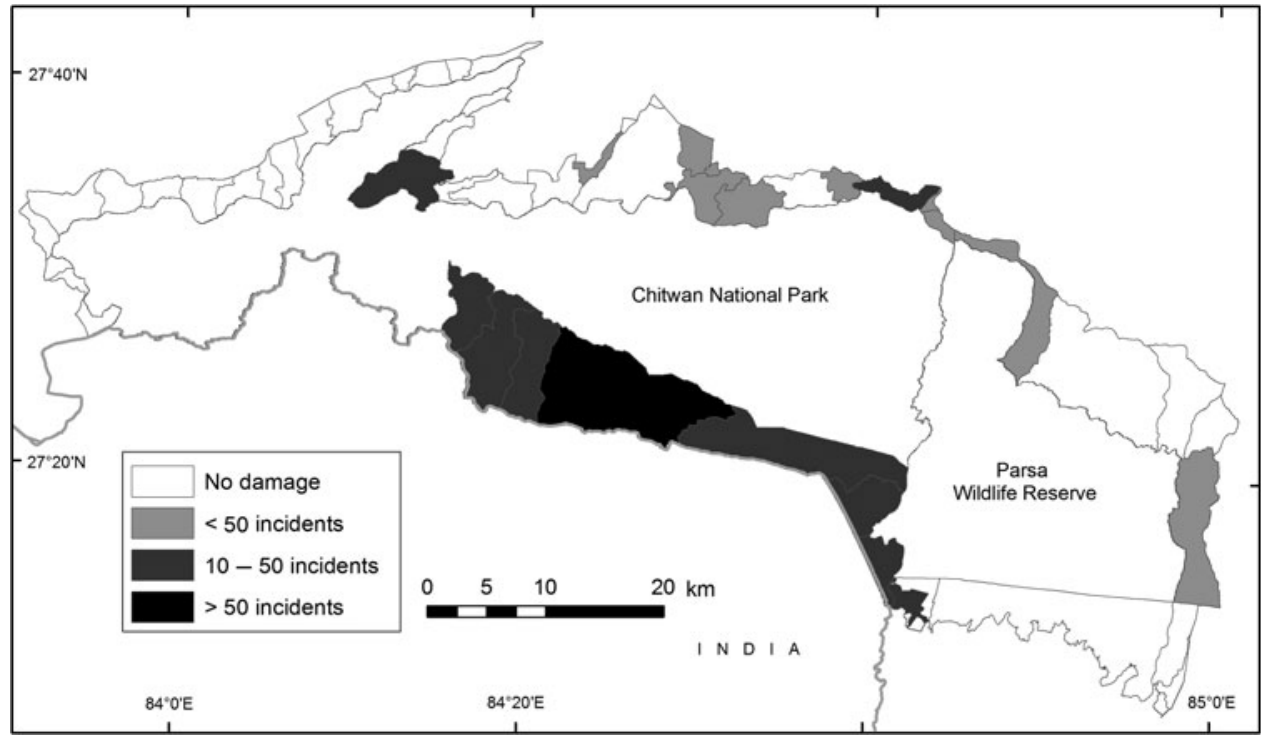

FIG. 4 Intensity of damage caused by elephants Elephas maximus in each village development committee and municipality in the buffer zones of Chitwan National Park and Parsa Wildlife Reserve (Fig. 1) during 2008-2012.

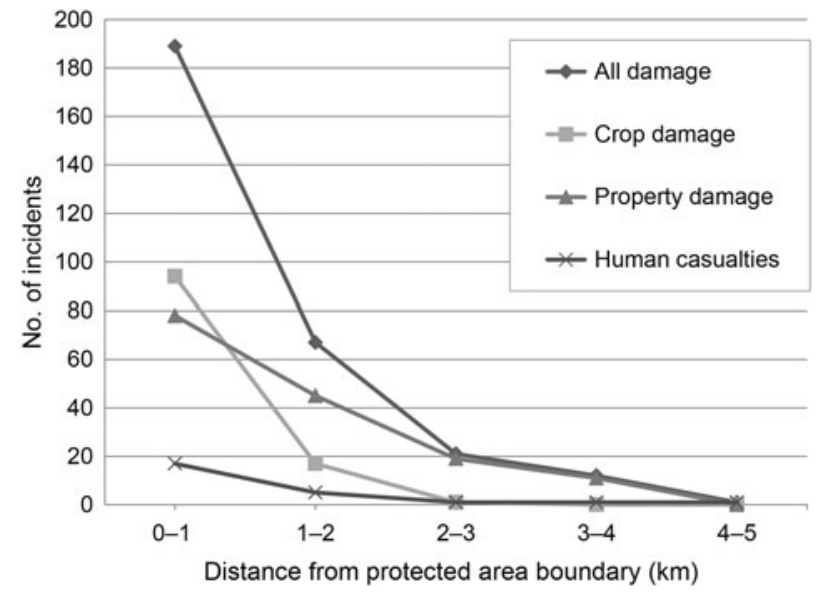

FIG. 5 Spatial distribution of incidents of human-elephant conflict in the buffer zones of Chitwan National Park and Parsa Wildlife Reserve (Fig. 1) in terms of distance from the protected area boundary.

crops (in summer and winter) are grown in the same fields if there is irrigation. The harvesting period for summer paddy is July-August and for winter paddy October-November (Subedi et al., 1993). According to park records there are two peaks in crop raiding, one in July and another during September-November, which coincide with the paddy harvesting periods. A similar pattern of crop raiding is observed in India, where crop raiding takes place during June-August and October-November for two types of paddy, one cultivated in shallow water and the other in deeper water (Lahkar et al., 2007).

Crop raiding is considered to be a normal seasonal phenomenon where crop fields are adjacent to elephant habitat, but property damage and human casualties are less predictable and tend to be caused by problem individuals. Patterns of human-elephant conflict are influenced most by the behaviour of individual elephants (Parker et al., 2007). More incidents of property damage compared to other types of damage in our study area may be attributed to the unpredictable raiding behaviour of male elephants. Most incidents of property damage and human casualties recorded in the study area occurred during December, when rice was stored in homes following the harvest in November.

Male elephants tend to follow a high risk, high gain strategy to promote reproductive success, and therefore they are more likely than members of a female-led family herd to raid agricultural crops and to kill people (Sukumar, 1991). Some males may become aggressive if confronted while raiding crops or stored grain; such problem elephants are responsible for the majority of incidents of conflict (Sukumar, 2006). In central Nepal conflict is caused by three types of elephants: (1) elephant herds that raid crops occasionally as they pass through crop fields during their seasonal movement, (2) single males or small groups of males that raid crops as an extension of their optimal foraging behaviour, and (3) problem elephants, which are habituated to take risks, and may cause human casualties while in the process of raiding crops and stored grain.

Spatial patterns of human-elephant conflict have shown few universal trends, which makes it difficult to predict where incidents will occur (Sitati et al., 2003). In general, conflict is highest in close proximity to protected areas that act as elephant refuges (DiFonzo, 2007), and the number of incidents decreases with increasing distance of villages from the forest boundary (Lahkar et al., 2007). In our study area the frequency of incidents was high within $1 \mathrm{~km}$ from the protected area boundary. The location of stables (hattisar) with captive female elephants is likely to be another determinant of the spatial distribution of human-elephant conflict. In western Nepal it was found 
that bull elephants damaged crops and properties mostly during the period when they came for oestrous females in the hattisar (Shrestha et al., 2007). This is also the case in central Nepal, where most of the settlements with a high frequency of incidents of human-elephant conflict are close to elephant stables established by protected area authorities.

The attitudes of the respondents towards elephant conservation were varied, and there was no statistically significant relationship between people's attitudes and the damage caused by elephants. This indicates that people can tolerate a certain level of damage by wildlife. This is further illustrated by the fact that in some cases people did not report crop damage to claim compensation. In the context of human safety, people's attitudes towards wildlife are more negative. Eight of nine respondents who lost a family member had a negative attitude towards elephant conservation. In December 2012 people staged a protest to kill a problem elephant that had killed a number of people in the vicinity of Chitwan National Park.

Our findings suggest that public awareness and compensation could help minimize conflict between people and elephants in central Nepal. Inadequate awareness of elephant behaviour is one of the main reasons for human casualties, as people come into direct contact with elephants in an effort to defend their crops and property. Awareness-raising activities for people living in conflict zones could help to build their capacity to avoid interactions with elephants and thus minimize conflict, and garner public support for elephant conservation.

Conflict could also be reduced by promoting the cultivation of crops that are unpalatable to elephants, and improvement in grain storage systems. Adequate and timely compensation for damage to crops and property could also help to foster more positive attitudes towards elephant conservation. Incidents of conflict could be reduced by avoiding the construction of elephant stables near villages, or at least moving the female elephants away from human settlements when they are in oestrous.

We organized a series of workshops during SeptemberDecember 2013 for the relevant protected area managers and local communities to communicate the key findings of this study, and we have presented the major findings of our study at a national-level workshop on management of human-wildlife conflict. Thus, we expect our findings will be considered in plans and actions to minimize human-elephant conflict, particularly in central Nepal. To ensure human-elephant coexistence in central Nepal we recommend the development and implementation of a conflict mitigation strategy, which will require a better understanding of temporal and spatial patterns of human-elephant conflict. As the spatial pattern is more difficult to predict than the temporal pattern, there is a need for more systematic recording and analysis to better understand the pattern of conflicts. The ecology and ranging behaviour of adult males and herds needs to be studied as a prerequisite for devising comprehensive strategies to minimize human-elephant conflict in this human-dominated landscape.

\section{Acknowledgements}

We extend our sincere thanks to the officials of the Department of National Parks and Wildlife Conservation, Nepal, for granting permission for this research and sharing information related to human-elephant conflict and its mitigation in Nepal. We are indebted to staff at Chitwan National Park and Parsa Wildlife Reserve for their support in collecting data. We thank the respondents of questionnaire surveys and key informant interviews for providing information and sharing ideas, and $\mathrm{Mr}$ Babu Ram Lamichhane, Wildlife Research Officer at National Trust for Nature Conservation Nepal, who helped in the preparation of maps. We acknowledge the financial assistance provided by the Rufford Small Grants Foundation.

\section{References}

BAJimaya, S. (2012) Managing human-wildlife conflict in Nepal. In Biodiversity Conservation in Nepal: A Success Story (eds K.P. Acharya \& M. Dhakal), pp. 21-34. Department of National Parks and Wildlife Conservation, Kathmandu, Nepal.

Bandara, R. \& Tisdell, C.A. (2003) Comparison of rural and urban attitudes to the conservation of Asian elephants in Sri Lanka: empirical evidence. Biological Conservation, 110, 327-342.

BARnes, R.F.W. (2009) The analysis of data from studies of crop-raiding. Gajah, 30, 19-23.

BASNET, R.B. (2011) Human-elephant conflict: comparing human perception on elephant population in central Nepal. BSc thesis. Tribhuvan University, Pokhara, Nepal.

BнаттA, S.R. (2006) Efforts to conserve the Asian elephant in Nepal. Gajah, 25, 87-89.

Campos-Arceiz, A., Takatsuki, S., Ekanayaka, S.K.K. \& Hasegawa, T. (2009) The human-elephant conflict in South-eastern Sri Lanka: type of damage, seasonal patterns, and sexual differences in the raiding behavior of elephants. Gajah, 31, 5-14.

CBS (Central Bureau of Statistics) (2011) Nepal Living Standards Survey 2010/11: Statistical Report, Volume 2. Central Bureau of Statistics, Kathmandu, Nepal.

Choudhury, A., Lahiri Choudhury, D.K., Desai, A., Duckworth, J.W., EasA, P.S., Johnsingh, A.J.T. et al. (2008) Elephas maximus. In The IUCN Red List of Threatened Species v. 2014.3. Http://www.iucnredlist.org [accessed 12 May 2015].

DiFonzo, M.M.I. (2007) Determining correlates of human-elephant conflict reports within fringe villages of Kaziranga National Park, Assam. MSc thesis. University of London, UK.

DNPWC (Department of National Parks and Wildlife Conservation) (2008) The Elephant Conservation Action Plan of Nepal. DNPWC, Kathmandu, Nepal.

DNPWC (Department of National Parks and Wildlife Conservation) (2012a) Chitwan National Park and Buffer Zone Management Plan 2012-2016. DNPWC, Kathmandu, Nepal.

DNPWC (Department of National Parks and Wildlife Conservation) (2012b) Parsa Wildlife Reserve and Buffer Zone 
Management Plan 2012-2016 (Final Draft). DNPWC, Kathmandu, Nepal.

DNPWC (Department of National Parks and Wildlife Conservation) (2014) Protected Areas of Nepal. Http://www. dnpwc.gov.np/index.php/page/41 [accessed 14 May 2015].

Hedges, S. \& Gunaryadi, D. (2010) Reducing human-elephant conflict: do chillies help deter elephants from entering crop fields? Oryx, 44, 139-146.

Hill, C.M. (1998) Conflicting attitudes towards elephants around the Budongo Forest Reserve, Uganda. Environmental Conservation, 25, 244-250.

HoAre, R. (1999) Determinants of human-elephant conflict in a landuse mosaic. Journal of Applied Ecology, 36, 689-700.

Hoare, R. (2000) African elephants and humans in conflict: the outlook for co-existence. Oryx, 34, 34-38.

Lahkar, B.P., Das, J.P., Nath, N.K., Dey, S., Brahma, N. \& Sarma, P.K. (2007) A Study of Habitat Utilization Patterns of Asian Elephant Elephas maximus and Current Status of Human Elephant Conflict in Manas National Park within Chirang-Ripu Elephant Reserve, Assam. A technical report prepared by Aaranyak, Guwahati, India.

Parker, G.E., Osborn, F.V., Hoare, R.E. \& Niskanen, L.S. (2007) Human-Elephant Conflict Mitigation: A Training Course for Community-Based Approaches in Africa. Participant's Manual. Elephant Pepper Development Trust, Livingstone, Zambia, and IUCN/SSC African Elephant Specialist Group, Nairobi, Kenya.

Perera, B. (2009) The human-elephant conflict: a review of current status and mitigation methods. Gajah, 30, 41-52.

Pradhan, N.M.B., Williams, A.C. \& Dhakal, M. (2011) Current status of Asian elephants in Nepal. Gajah, 35, 87-92.

Redpath, S.M., Bhatia, S. \& Young, J. (2015) Tilting at wildlife: reconsidering human-wildlife conflict. Oryx, 49, 222-225.

Røskaft, E., Händel, B., Bjerke, T. \& Kaltenborn, B.P. (2007) Human attitudes towards large carnivores in Norway. Wildlife Biology, 13, 172-185.

Shrestha, R., Bajracharya, S.B. \& Pradhan, N.M.B. (2007) A Case Study on Human-Wildlife Conflict in Nepal with Particular Rreference to Human-Elephant Conflict in Eastern and Western Terai Regions. Report submitted to WWF Nepal Programme, Kathmandu, Nepal.

Sitati, N., Walpole, M., Smith, R. \& Leader-Williams, N. (2003) Predicting spatial aspects of human-elephant conflict. Journal of Applied Ecology, 40, 667-677.

Smith, J.L.D. \& Mishra, H.R. (1992) Status and distribution of Asian elephants in Central Nepal. Oryx, 26, 34-38.
Subedi, B.P., Das, C.L. \& Messerschmidt, D.A. (1993) Tree and Land Tenure in the Eastern Terai, Nepal: A Case Study from the Siraha and Saptari Districts, Nepal. FAO Community Forestry Case Study 9. Http://www.fao.org/docrep/v2670e/v267oeoo.htm [accessed 14 May 2015].

Sukumar, R. (1990) Ecology of the Asian elephant in southern India. II. Feeding habits and crop raiding patterns. Journal of Tropical Ecology, 6, 33-53.

SUKUMAR, R. (1991) The management of large mammals in relation to male strategies and conflict with people. Biological Conservation, 55, 93-102.

Suk umar, R. (1993) The Asian Elephant: Ecology and Management. Cambridge University Press, Cambridge, UK.

Sukumar, R. (2006) A brief review of the status, distribution and biology of wild Asian elephants Elephas maximus. International Zoo Yearbook, 40, 1-8.

Thirgood, S., Woodroffe, R. \& Rabinowitz, A. (2005) The impact of human-wildlife conflict on human lives and livelihoods. Conservation Biology Series-Cambridge, 9, 13.

Wilson, S., Davies, T.E., Hazarika, N. \& Zimmermann, A. (2015) Understanding spatial and temporal patterns of human-elephant conflict in Assam, India. Oryx, 49, 140-149.

ZHANG, L. \& WANG, N. (2003) An initial study on habitat conservation of Asian elephant (Elephas maximus), with a focus on human elephant conflict in Simao, China. Biological Conservation, $112,453-459$.

\section{Biographical sketches}

GANesh PAnt works on protected area management in Nepal, and is particularly interested in human dimensions of biodiversity conservation. MAHESHWAR DHAKAL specializes in natural resource economics, and his research interests include the policy and socio-economic analysis of protected area management. NARENDRA MAN BABU PRADHAN worked at the Department of National Parks and Wildlife Conservation, Nepal, for 22 years before joining WWF Nepal in 2011. He is interested in wildlife ecology and conservation biology. Fiona LEVERINGTON is a member of the IUCN World Commission on Protected Areas, and her interests include protected area management, reserve selection and community engagement. Marc Hockings is Vice-Chair of the IUCN World Commission on Protected Areas, and his research focuses on evaluating the effectiveness of protected area management. 